\title{
Social Dimension of Web 2.0 in Teacher Education: Pedagogical Guidelines
}

\author{
Andreas Ahrens \\ Hochschule Wismar, Germany
}

\author{
Jel̦ena Zaščerinska \\ University of Latvia, Latvia
}

\begin{abstract}
The research deals with the analysis of efficiency of the process of teaching and learning with use of the social dimension of Web 2.0 within the English for Specific Purposes course in pre-school and primary teacher education that would help students to become more cognizant and more responsive to the emerging needs of the market for educational services and to promote their use of the social dimension of Web 2.0. The analysis involves a process of analyzing the meaning of the key concepts "social dimension of Web 2.0", "teaching and learning" and "peer-learning”. Moreover, the study demonstrates how the key concepts are related to the idea of "efficiency". The paper introduces the study conducted in Latvia in 2008-2009. The conducted explorative research has been used. The sample involved 47 pre-school and primary student teachers. Descriptive statistics were implemented for primary data analysis. The findings of the research allow drawing conclusions on efficiency of the process of teaching and learning with use of the social dimension of Web 2.0. Directions of further research on the development of student's personal experience in use of the social dimension of Web 2.0 as a condition for creation of new knowledge are elaborated.
\end{abstract}

\section{Introduction}

The social dimension of Web 2.0 penetrates our society more thoroughly with the availability of broadband services. Web 2.0 is jointly formed by four dimensions, namely, the infrastructure dimension, the functionality dimension, the data dimension, and the social (or socialization) dimension as depicted in Figure 1.

Socialization, described as taking software or even user-generated content and sharing or jointly using it with others, covers the aspect of usergenerated content as it occurs in blogs or wikis, in tagging as well as in social bookmarking [1]. Skype, Classroom Management Systems, the eBay seller evaluation, the Amazon recommendation service, or Wikipedia, where the increased data exchange within the system is no longer a limiting parameter with the current developments in the infrastructure, are classical examples and have found widespread acceptance in the community.

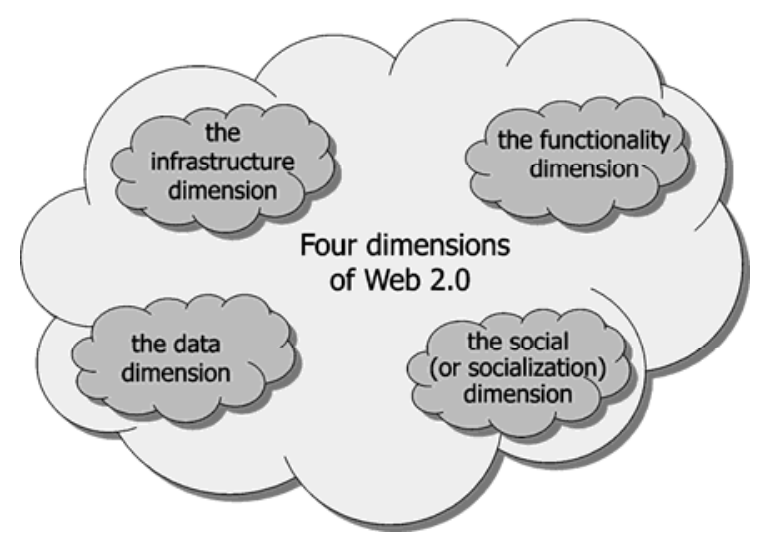

Figure 1. Four dimensions of Web 2.0

Teachers are the key actors in promoting pupils' use of Information and Communication Technology. Therein, there are high demands on teachers in providing pupils as prospective specialists with a proper use of the social dimension of Web 2.0.

However, the success of the social dimension of Web 2.0 in teacher education requires efficiency of the process of teaching and learning with use of the social dimension of Web 2.0 in pre-school and primary teacher education to be considered.

The meaning of the key concepts of "social dimension of Web 2.0", "teaching and learning" and "peer-learning" is studied. Moreover, the study demonstrates how the key concepts are related to the idea of "efficiency". The study shows a potential model for development, indicating how the steps of the process are related following a logical chain: the social dimension of Web $2.0 \rightarrow$ the process of teaching and learning with use of the social dimension of Web 2.0 in pre-school and primary teacher education $\rightarrow$ empirical study within a multicultural environment.

The conceptual framework of the present research is based on the relationship between teaching and learning.

The methodological foundation of the present research is based on the System-Constructivist Theory that includes:

- Parsons's system theory [2] on any activity as the system, 
- Luhmann's theory [3] on communication as a system,

- theory of symbolic interactionalism [4] and

- theory of subjectivism [5].

- The System-Constructivist Theory and, consequently, the system-constructivist approach to learning introduced by Reich [6] emphasize that

- human being's point of view depends on the subjective aspect and

- experience plays the central role in the knowledge construction process [7].

The remaining part of this paper is organized as follows: Section 2 introduces the theoretical framework of the social dimension of Web 2.0 and the process of teaching and learning with use of the social dimension of Web 2.0 within pre-school and primary teacher education. Research design is revealed in Section 3. The associated empirical results are presented and interpreted in Section 4. Finally, some concluding remarks and directions of further studies are elaborated in Section 5.

\section{Theoretical Framework}

The theoretical framework of the present contribution involves the meaning of the key concepts of "social dimension of Web 2.0", "teaching and learning" and "peer-learning" to be studied.

\subsection{Social dimension of Web 2.0}

Typical social dimension of Web 2.0 techniques and technologies include "social software" and online social networks [1].

"Social software" is defined by Vossen [1] as software that gets better (or at least more useful) the more people use it. While most of the time the software itself, i.e., the program system, does not change based on the number of its users or the frequency with which it is used, it is the application that the software is enabling. Examples include Skype, the eBay seller evaluation, the Amazon recommendation service, or Wikipedia. Especially the latter is a perfect example for what so-called mass collaboration [8] or crowdsourcing can achieve.

Vossen [1] considers that online social networks, another form of mass socialization today, bring a dimension to the Web that goes beyond simple links between pages; they add links between people and between communities. In such a network, direct links will typically point to our closest friends and colleagues, indirect links lead to the friends of a friend, and etc.

A social network on the Web is typically the result of employing some software that is intended to focus on building an online community for a specific purpose. Social networks connect people with common interests and may be as simple as a blog, or as complex as Facebook or MySpace for mostly private applications, as LinkedIn or Xing for professional applications, or as Twitter for both. The primary impact that the current Web developments are having in this area are that connecting people and communities constantly becomes easier, and it is not difficult anymore to maintain a professional or personal network of buddies worldwide. Yet another impact is that a social network may open up novel sources of revenue, in particular through advertising. Finally, Vossen [1] underlines that two aspects should have become clear by the discussion so far: on the one hand, the most obvious change that has recently occurred on the Web is that it has changed from a pure read Web as designed by Berners-Lee [9] to a read/write Web, where users not only draw information from, but also add information to it. On the other hand, the dimensions we have discussed exhibit various overlaps. Indeed, technology enables functionality, which as a "byproduct" leads to data collections, and users have a new tendency to socialize over the Web, by exploiting that functionality and the technology.

Hence, the paradigm change, namely, the move towards mass collaboration [8] and/or mass socialization [1], puts the emphasis on social dimension of Web 2.0 techniques and technologies to be integrated into the processes and environments of pre-school and primary teacher education.

\subsection{Social dimension of Web 2.0 in pre- school and primary teacher education}

The change in teacher entering the service area, namely, not working permanently at an educational institution but accepting project-related orders of educational institutions [10] reveals the significance of use of the social dimension of Web 2.0 in the process of teaching and learning of pre-school and primary teacher education.

The search for the integration of social dimension of Web 2.0 techniques and technologies into preschool and primary teacher education reveals that the software programmes following the traditional stimulus-response model based on behaviourism lead to the computers' misuse. A proper integration of social dimension of Web 2.0 techniques and technologies into pre-school and primary teacher education is based on the process of interiorization [11].

The process of teaching and learning is defined as shared aim oriented joint activity according to certain common norms, over some period of time that provides joint social interaction and cognition for each participant and increases opportunities of gaining social experience. The scientific novelty of the process of teaching and learning reveals the content development, the content process and 
procedural aspect of the content within the tertiary gradual process of teaching and learning, namely,

- from the educator-student interaction with use of the social dimension of Web 2.0,

- through the peer-interaction with a variety in use of the social dimension of Web 2.0 and

- to the student's action for the improvement of use of the social dimension of Web 2.0.

Thus, a proper integration of social dimension of Web 2.0 techniques and technologies in pre-school and primary teacher education gradually moves from teaching in Phase 1 to learning in Phase 3 through peer-learning in Phase 2 as shown in Figure 2 by Zaščerinska and Ahrens [12]. Each phase of the process of teaching and learning is separated from the previous one, and the following phase is based on the previous one.

The teaching phase starts with preparing the students for the process of teaching and learning, planning the procedure of the process of teaching and learning, equipping teaching/learning class, determining the purpose, etc. Then, the peer-learning phase is aimed at doing an exercise and making a decision. The learning phase focuses on the evaluation of both individual achievements and results. Students gradually move from the external regulation and evaluation in Phase 1 to the selfregulation, mutual evaluation and self-evaluation in Phase 3.

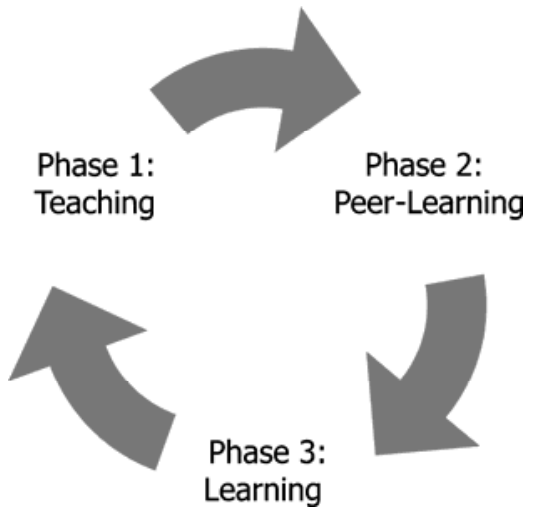

Figure 2. Phases of the process of teaching and learning with use of the social dimension of Web 2.0 in teacher education

The process of teaching and learning with use of the social dimension of Web 2.0 is implemented as following: Phase 1 of implementing of the process of teaching and learning with use of the social dimension of Web 2.0 is aimed at a safe environment for all the students. In order to provide a safe environment, the essence of constructive social interaction and its organizational regulations are considered by both the educator and students. The present phase of the process of teaching and learning with use of the social dimension of Web 2.0 is organized in a frontal way involving the students to participate, namely,

- Educator makes previous experience rational. The activity includes choice of forms and use of resources that motivates the students. Teaching process is under the educator's guidance.

- Peers do not participate in guidance of the process of teaching and learning. Activity is carried out qualitatively only with the help of the educator. Dependence on the educator is observed. The students study alongside but not together.

- Students create the system of the aim and objectives, search for a variety of information source and obtain techniques of information compiling. Students fulfil the activity qualitatively only with the educator's help. Dependence on the educator is observed, not dependent on peers.

Phase 2 of implementing of the process of teaching and learning with use of the social dimension of Web 2.0 is designed for the students' analysis of an open academic problem situation and their search for a solution. This phase of the process of teaching and learning with use of the social dimension of Web 2.0 involves the students to act in peers, namely,

- Educator functions as a resource and moderator. Educator delegates his/her duties to the students.

- Peers regulate each other: it is typical for students to regulate each other. The students study together, study from others and teach others. The process of teaching and learning is under peer's guidance. Activity's forms and methods are exchanged.

- The students fulfil the activity qualitatively with the peers' help. Partial independence is observed. The relevant activity is performed jointly with other students and with shared responsibility. It is typical for students to regulate each other.

Phase 3 of implementing of the process of teaching and learning with use of the social dimension of Web 2.0 emphasizes the students' selfregulation with use of assessment of the process and self-evaluation of the results, namely,

- Educator functions as a consultant and an assistant. Educator delegates his/her duties to the students.

- Peers have consultative and advisory functions. Students' self-regulation is typical. The students study independently.

- The students fulfil the activity qualitatively on their own, and their independence is observed. The participants' self-regulation on the basis of the process assessment and the result selfevaluation is used. The relevant activity is performed with a high sense of responsibility. 
Self-regulation is typical, and a student does not depend on peers.

Thus, the advantages of the process of teaching and learning with use of the social dimension of Web 2.0 are determined as following:

- widening opportunities for each student to construct the experience in social interaction and cognitive activity, that is a significant aspect of the students' experience in use of the social dimension of Web 2.0 and

- $\quad$ promoting opportunities for self-realization.

All learning is part of a single process, an ongoing process [7]. This finding suggests that learning and/or e-learning are part of a single learning process in teacher education. Hence, teacher education is formed by student learning that comprises e-learning.

\section{Research Design}

The research design within the present research comprises the research purpose and question, the sample of the present research and the research methodology to be considered.

\subsection{The research purpose and question}

The present research was conducted during the implementation of the process of teaching and learning with use of the social dimension of Web 2.0 within the English for Specific Purposes courses in the four-year professional Bachelor's study programmes Teacher of Pre-School Education and Teacher of Pre-School and Primary School Education of Riga Teacher Training and Educational Management Academy, Latvia, from September 2008 to May 2009 to examine efficiency of the process of teaching and learning with use of the social dimension of Web 2.0 within the English for Specific Purposes courses in pre-school and primary teacher education in order to promote the use of the social dimension of Web 2.0 by pre-school and primary student teachers. Its topicality is determined by ever-increasing flow of information in which an important role is laid to the social dimension of Web 2.0 as a means of getting information and gaining experience.

The research question is as follows: Has the process of teaching and learning with use of the social dimension of Web 2.0 been efficient?

It should be mentioned that efficiency involves quality and effectiveness. Quality is an idea of what are the "right things" that we are doing, and procedures for checking that we are "doing things right" [13]. Effectiveness is the aim achievement at a certain quality spending minimal time and energy. The process of teaching and learning with use of the social dimension of Web 2.0 is efficient if the inputs (opportunities of gaining experience, namely, the process of teaching and learning with use of the social dimension of Web 2.0) produce the maximum output [14] (students' experience in use of the social dimension of Web 2.0).

\subsection{The sample of the research}

The sample selecting 22 pre-school student teachers and 25 pre-school and primary student teachers of Riga Teacher Training and Educational Management Academy in Latvia was composed. All 47 pre-school and primary student teachers are at the beginning of the third semester in the second year of their Bachelor studies.

The sample with different cultural backgrounds and diverse educational approaches was selected. Whereas cultural similarity aids mutual understanding between people [15], the students' different cultural and educational backgrounds contribute to successful learning and become an instrument of bringing the students together more closely under certain conditions. These conditions include appropriate teaching materials, teaching and learning methods and forms, motivation and constructive positioning of the educator. Moreover, the paradigm has shifted from focusing on macrocultures to micro-cultures (family culture, school culture, class culture, professional culture, gender culture, culture of interest groups, political groups/parties, generation) that leads to understanding that people behave being influenced by identification with different groups, not only one group [16]. Thus, the sample of the present research is multicultural.

The sample consisted of 47 female students which is a typical representation to the proportion of male and female pre-school and primary teachers in schools of Latvia. The age of the sample was from 19 to 24.34 of the pre-school and primary student teachers had no working experience. 13 pre-school and primary student teachers had working experience in the fields different from their future profession. Regarding their working experience the following fields were mentioned: voluntary social work, tourism industry and advertising industry. 30 of the students had certain expectations from the Bachelor programme and, consequently, from the English for Specific Purposes course, which were demonstrated in the answer to the question why they had chosen that programme. The use of Information and Communication Technology that includes the social dimension of Web 2.0 in the studies was one of the answers.

\subsection{Research methodology}

An explorative qualitative research has been aimed at the development of general statements which can be tested for generality in following studies with different people in different times [17]. 
The study consisted of the following stages: exploration of the contexts in use of Web 2.0 in Latvia; thorough analysis of the documents, analysis of the students' feedback regarding their needs (content analysis), data processing, analysis and data interpretation and analysis of the results and elaboration of conclusions and directions for further studies.

Moreover, checking the efficiency of pedagogic interventions and organizational changes in complex and constantly self-regenerating environments employs the qualitative evaluation research [18]. The basic directions of the development of the qualitative evaluation research are determined as following [19]:

- from diagnostic evaluation in Phase 1 through formative evaluation in Phase 2 to summative evaluation in Phase 3,

- from context analysis in Phase 1 through description of the practice in Phase 2 to generalization of the model in Phase 3,

- from thorough analysis of the documents in Phase 1 through surveys in Phase 2 to interviews in Phase 3 ,

- from structuring content analysis in Phase 1 through statistical analysis in Phase 2 to summarizing content analysis in Phase 3 and

- from self-evaluation in Phase 1 through internal evaluation in Phase 2 to external evaluation in Phase 3.

The phase of exploration of the context analysis of the qualitative evaluation research is aimed at determining the present situation of the process of teaching and learning with use of the social dimension of Web 2.0 in promoting the students' motivation and their readiness to implement the joint activity. The description of the practice analyzes differences in the level of features researched. Needs analysis of three levels, namely, individual, organizational and professional, serves as a basis for designing a questionnaire to analyze the efficiency of the process of teaching and learning with use of the social dimension of Web 2.0 by the pre-school and primary student teachers. The phase of generalization of the model determines whether the implementation of the process of teaching and learning with use of the social dimension of Web 2.0 is efficient.

\section{Empirical Results}

The empirical results of the present study reveal the contexts in use of Web 2.0 in Latvia through thorough analysis of the documents, analysis of two surveys of the students' feedback regarding their needs (content analysis) before and after educators' contribution to the students' experience in use of the social dimension of Web 2.0 and external evaluation of the research results.

\subsection{Tertiary teaching-learning in computer science in Latvia}

The goal of studies in the four-year Bachelor's programme is to prepare the bachelor as a universityeducated operational professional for all fields of pre-school and primary teacher education with a basic knowledge of the relevant theories and with practical skills. A graduate has the opportunity to continue in the study of the pre-school and primary teacher education fields or other related fields in the Master's study programme.

Computer learning has not been set as a goal of the Bachelor programmes Teacher of Pre-School Education and Teacher of Pre-School and Primary School Education in Riga Teacher Training and Educational Management Academy. It has to be mentioned that in the year 2008 there were no special requirements as the level of digital competence to study in the respective programme. Thus by providing pedagogical support to pre-school and primary student teachers and by using the social dimension of Web 2.0 in mastering academic content and, consequently, English for Specific Purposes (teaching-learning aids in an understandable language, consultancy, e-platform for collaborative work) students with different cognitive abilities transfer computer knowledge from one course to another.

The professional bachelor study programmes Teacher of Pre-School Education and Teacher of Pre-School and Primary School Education provide the English for Specific Purposes courses to facilitate students' research success, to support preparation for international Master and Ph.D. programmes in the European Union, further specialization in pre-school and primary teacher education and learning in a simulated environment.

The aim of the English for Specific Purposes course is determined as to improve pre-school and primary student teachers communicative competence in English for the participation in international research activities.

The process of teaching and learning with use of the social dimension of Web 2.0 within the English for Specific Purposes course involved a variety of teaching/learning activities with use of the social dimension of Web 2.0, namely, discussion, prepared talk and communication games and information-gap activities, to promote use of the social dimension of Web 2.0 by the pre-school and primary student teachers.

\subsection{Survey analysis}

The following questionnaire was used to analyze efficiency of the process of teaching and learning with use of the social dimension of Web 2.0 by the pre-school and primary student teachers: 
a) Question 1: Do you know the word Web 2.0?

b) Question 2: Do you know the basic idea of Web 2.0 ?

c) Question 3: Have you already used Web 2.0, namely, Facebook, Twitter, Wikipedia, etc?

d) Question 4: Do you think Web 2.0 requires a lot of profound knowledge, namely, math, physics, etc?

e) Question 5: Do you think Web 2.0 is useful for your individual needs?

f) Question 6: Do you think Web 2.0 is useful for your organizational use?

g) Question 7: Do you think Web 2.0 is useful for your professional use?

The evaluation scale of five levels for each question is given where " 1 " means "disagree" and low level of experience in social dimension of Web 2.0 technologies and " 5 " points out "agree" and high level of the social dimension of Web 2.0.

Survey 1 (Figure 3 and 4) reveals that use of the social dimension of Web 2.0 by the pre-school and primary student teachers is heterogeneous as well as the pre-school and primary student teachers do not realize the possibilities offered by Web 2.0 properly.

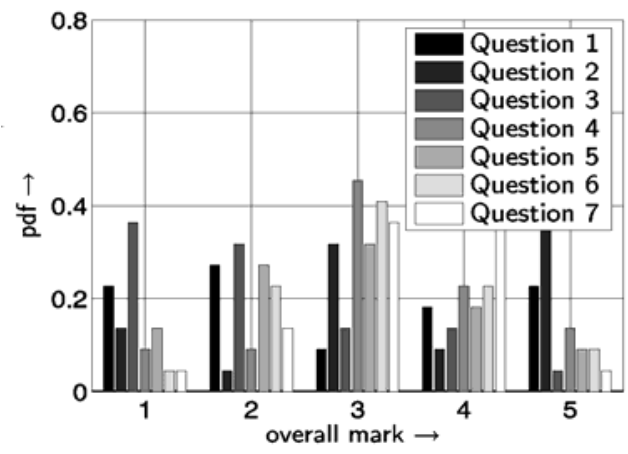

Figure 3. PDF (probability density function) of the pre-school student teachers' evaluation in September 2008

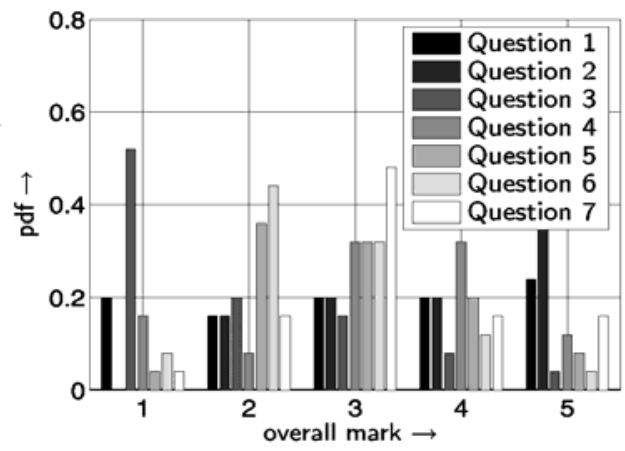

Figure 4. PDF (probability density function) of the primary student teachers' evaluation in September 2008
Between Survey 1 and 2 the process of teaching and learning with use of the social dimension of Web 2.0 within the English for Specific Purposes course involved a variety of teaching/learning activities with use of the social dimension of Web 2.0, namely, discussion, prepared talk and communication games and information-gap activities to promote use of the social dimension of Web 2.0 by the pre-school and primary student teachers.

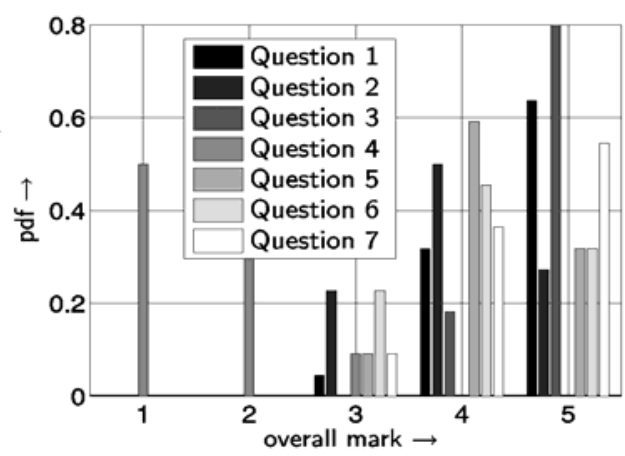

Figure 5. PDF (probability density function) of the pre-school student teachers' evaluation in May 2009

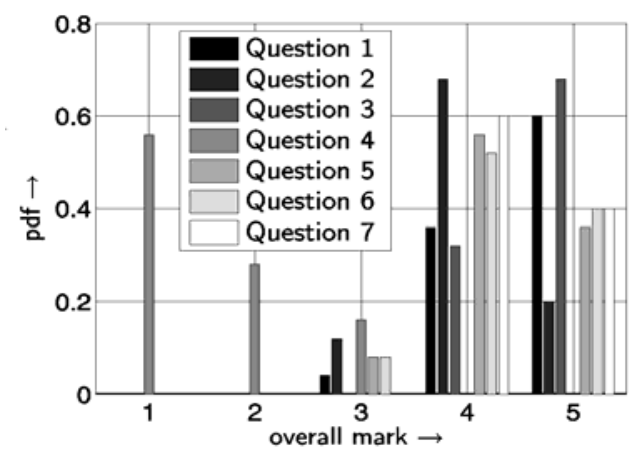

Figure 6. PDF (probability density function) of the primary student teachers' evaluation in May 2009

Then, the analysis of the second survey (Figure 5 and 6) reveals that the pre-school and primary student teachers' experience in use of the social dimension of Web 2.0 has become homogeneous and the pre-school and primary student teachers have put the emphasis on the use of Web 2.0 for professional purposes as shown in Table 1 .

The comparison of the Mean value (Mean) shows that the pre-school student teachers and pre-school and primary student teachers demonstrate the homogeneous experience (Mean value $-2,98$ and 3,01 in Survey 1 and 3.97 and 3.98 in Survey 2 respectively) in use of the social dimension of Web 2.0 technologies in both surveys. Hence, the results of Mean within the surveys of the students' experience in use of the social dimension of Web 2.0 technologies reveal that most of answers are 
concentrated around Level 3 and 4 that means "agree". Thus, there is a possibility to increase the students' experience in use of the social dimension of Web 2.0 technologies.

Table 1: Mean analysis of the questionnaires obtained from the pre-school student teachers and pre-school and primary student teachers

\begin{tabular}{|c|c|c|c|c|}
\hline \multirow{2}{*}{$\begin{array}{c}\text { Ques- } \\
\text { tion }\end{array}$} & \multicolumn{2}{|c|}{$\begin{array}{c}\text { Pre-school student } \\
\text { teachers }\end{array}$} & \multicolumn{2}{c|}{$\begin{array}{c}\text { Pre-school and } \\
\text { primary student } \\
\text { teachers }\end{array}$} \\
\cline { 2 - 5 } & $\begin{array}{c}\text { Mean } \\
\text { Survey } \\
1\end{array}$ & $\begin{array}{c}\text { Mean } \\
\text { Survey } \\
2\end{array}$ & $\begin{array}{c}\text { Mean } \\
\text { Survey } \\
1\end{array}$ & $\begin{array}{c}\text { Mean } \\
\text { Survey } \\
2\end{array}$ \\
\hline 1 & 3,09 & 4,59 & 2,88 & 4,56 \\
\hline 2 & 2,41 & 4,05 & 2,08 & 4,08 \\
\hline 3 & 3,82 & 4,82 & 4,08 & 4,68 \\
\hline 4 & 2,77 & 1,59 & 2,84 & 1,60 \\
\hline 5 & 3,18 & 4,23 & 3,08 & 4,28 \\
\hline 6 & 2,91 & 4,09 & 3,40 & 4,32 \\
\hline 7 & 2,73 & 4,45 & 2,76 & 4,40 \\
\hline Total & $\mathbf{2 , 9 8}$ & $\mathbf{3 , 9 7}$ & $\mathbf{3 , 0 1}$ & $\mathbf{3 , 9 8}$ \\
\hline
\end{tabular}

Processing, analysis and interpretation of data gathered from the surveys of the pre-school and primary student teachers' experience in the course of the present empirical study reveal that the process of teaching and learning with use of the social dimension of Web 2.0 in teacher education contributes to the use of the social dimension of Web 2.0 by the pre-school and primary student teachers.

\subsection{Analysis of the external evaluation of the research results}

The analysis of the external evaluation of the research results comprised the non-structured interview. The non-structured interviews included one question as following: what is the researcher's view on the present research on the process of teaching and learning with use of the social dimension of Web 2.0 for the development of students' use of the social dimension of Web 2.0? The aim of the non-structured interviews was to reveal the researchers' view on the process of teaching and learning with use of the social dimension of Web 2.0 for the development of students' use of the social dimension of Web 2.0.

Researcher EER1 emphasized use of the phases of the process of teaching and learning with use of the social dimension of Web 2.0 in studies of other foreign languages. The researcher underlined that the English for Specific Purposes course is clearly- and well-organized. Researcher EER1 considered that the English for Specific Purposes course provides the development of students' use of the social dimension of Web 2.0.
Researcher EER2 revealed that the present research on the process of teaching and learning with use of the social dimension of Web 2.0 for the development of students' use of the social dimension of Web 2.0 includes a great deal of valuable discussion.

Researcher EER3 considered the organization model of the process of teaching and learning for the development of students' use of the social dimension of Web 2.0 to be a transformative methodology. The researcher emphasized that the idea of positioning the quasi-concept within the quasi-autonomous zone is fascinating for further research in education. Researcher EER3 determines that Vygotsky's Law of Development selected could be highly successful in practice because educators can indeed change the typical classroom environment. The researcher stressed that focus on establishing a system allows viewing the overall personality of the learner and connecting the external with the internal. Moreover, the scheme titled "Organisation of Efficient Academic Environment" includes both external and internal factors. This scheme presents the unique approach where the basic directions of the development of the organization model of the process of tertiary teaching and learning proceed from existing knowledge through knowledge variety to knowledge improvement. The approach provides the student with having the "ability to create knowledge". Moreover, newer constructs that will truly help the student to internalize new material have been developed.

Researcher EER4 emphasized the conditions, criteria, indicators and levels of the development of students' use of the social dimension of Web 2.0 to be important for the innovative process in education.

Researcher EER5 found the approach used for the development of students' use of the social dimension of Web 2.0 promising and worthwhile.

Researcher EER6 revealed the present research on the process of teaching and learning for the development of students' use of the social dimension of Web 2.0 to be argumentative in which both the methodological and theoretical underpinning are described.

Researcher EER7 put the emphasis on the use of the process of teaching and learning in master and $\mathrm{PhD}$ studies. Moreover, the researcher proposed a foreign language educator to be a non-native speaker in order to focus the students on the contents of the English for Specific Purposes course.

Researcher EER8 found the present research to be very interesting and thought-provoking considerations for the practice of language teaching at university level in particular.

Researcher EER9 found the research on efficiency of the process of teaching and learning for the development of students' use of the social dimension of Web 2.0 in language education to be a 
very well conducted piece of research, which reaches some interesting conclusions. From the researcher's view, the analysis is comprehensive, and the conclusions are viable.

Summarizing content analysis [20] of the data reveals that the respondents evaluate the process of teaching and learning with use of the social dimension of Web 2.0 for the development of students' use of the social dimension of Web 2.0 positively. The researchers' external evaluation validates the findings of the present research. Thus, the conclusion can be drawn that the implementation of the process of teaching and learning with use of the social dimension of Web 2.0 enhances students' use of the social dimension of Web 2.0.

\section{Discussion}

The findings of the research allow drawing conclusions on the efficiency of the process of teaching and learning with use of the social dimension of Web 2.0 within the English for Specific Purposes course in pre-school and primary teacher education.

Regarding efficiency of the contribution to the pre-school and primary student teachers' use of the social dimension of Web 2.0 it is evident that the pre-school and primary student teachers widened their experience in use of the social dimension of Web 2.0 for organizational and professional purposes with the implementation of the support system within the English for Specific Purposes course in preschool and primary teacher education.

Data validity has been provided by the method and data triangulation. The validity of the qualitative evaluation research has been shown by use of the mixed methods' approach to the data processing and analysis. Validity and reliability of the research results have been demonstrated by involving other researchers into the empirical study in several stages of the conducted research. As well as the external validity has been revealed by international cooperation, namely, working out this paper in cooperation with international colleagues as well as the paper assessment by the international colleagues on the basis of co-operation between the universities and presentations of the research at international conferences.

Therein, the researchers' external evaluation validates the findings of the present research. Thus, the conclusion can be drawn that the implementation of the process of teaching and learning with use of the social dimension of Web 2.0 enhances students' use of the social dimension of Web 2.0. Hence, the process of teaching and learning with use of the social dimension of Web 2.0 for the development of students' use of the social dimension of Web 2.0 influences and determines the students' success or failure for acquiring other university courses and profession.

Thus, it might be stressed that the process of teaching and learning with use of the social dimension of Web 2.0 is efficient if it provides student's personal experience in use of the social dimension of Web 2.0 for organizational and professional purposes as conditions for creation of new knowledge:

- if students' learning experience is supported by the process of teaching and learning with use of the social dimension of Web 2.0 for organizational and professional purposes, students attain better learning outcomes, and

- if students' needs are met and a support system is created that would secure their experience in use of the social dimension of Web 2.0 for organizational and professional purposes, students demonstrate better learning outcomes, too.

The present research has limitations. A limitation is the empirical study conducted by involving the students and educators at bachelor level of one tertiary institution. Therein, the results of the study cannot be representative for the whole country. As well as the empirical study outlines the opportunities of the development of students' experience in use of the social dimension of Web 2.0. Nevertheless, the results of the research, namely, the phases of the process of teaching and learning with use of the social dimension of Web 2.0 and the explorative qualitative research design, may be used as a basis of the development of students' experience in use of the social dimension of Web 2.0 at bachelor and master levels of other tertiary institutions. If the results of other tertiary institutions had been available for analysis, different results could have been attained. There is a possibility to continue the study.

The results of the theoretical and empirical research could be particularly useful for educators who promote the development of the Information and Communication Technology-based economy enabling new specialists to act in a constantly changing multicultural environment. Thus, the implementation of the process of teaching and learning with use of the social dimension of Web 2.0 determines the need in promoting pre-service and inservice training for student educators to succeed in a successful implementation of the process of teaching and learning with use of the social dimension of Web 2.0.

The following sequence of the implementation of the process of teaching and learning with use of the social dimension of Web 2.0 is proposed:

- Phase 1 is aimed at determining the notion of constructive social interaction and its organizational regulation,

- Phase 2 is designed for the students' analysis of an open academic problem situation and their search for its solving that provide each student 
with the opportunity to construct his/her own social experience, and

- Phase 3 emphasizes the students' self-regulation with use of evaluation of the process and selfevaluation of the result.

Moreover, the recommendation here is the role of educators as mentors for students' self-discovery and self-realization; to motivate students, to stimulate their interests, to help them to develop their own structure and style, as well as to help them to evaluate their performance and be able to apply these findings [7] to improve their use of the social dimension of Web 2.0. The role of educators as mentors demands the educators to develop continuously their experience in social interaction and cognitive activity.

In order to provide each student the opportunity to construct his/her own social experience, the results of the theoretical and empirical research for practical purposes outline communication games, informationgap activities, role plays, simulations, dialogues, prepared talks and discussions for the improvement of students' experience in use of the social dimension of Web 2.0.

The process of teaching and learning with use of the social dimension of Web 2.0 and, particularly, the sequence of its implementation developed and validated in practice during the present research could be widely used in the pedagogical process. The process of teaching and learning with use of the social dimension of Web 2.0 can be easily integrated into university's courses, exchange programs, tutorials for introduction into advanced research topics, participation in a conference, tutorials and practical tasks, language training for specific purposes, leisure activities and social contacts, practical work in a company for the knowledge development.

Further research on the process of teaching and learning with use of the social dimension of Web 2.0 for the development of students' experience in use of the social dimension of Web 2.0 within a multicultural environment is intended to analyze the development of both the educator's and student's experience in use of the social dimension of Web 2.0 within the process of teaching and learning with use of the social dimension of Web 2.0.

Another direction of further research might include the development of students' experience in use of the social dimension of Web 2.0 within five phases of the process of teaching and learning with use of the social dimension of Web 2.0. Hence, the development of students' experience in use of the social dimension of Web 2.0 can be analyzed in the following process of teaching and learning with use of the social dimension of Web 2.0:

- teaching with use of the social dimension of Web 2.0 in Phase 1,
- teaching with elements of peer-learning with use of the social dimension of Web 2.0 in Phase 2,

- peer-learning with use of the social dimension of Web 2.0 in Phase 3,

- peer-learning with elements of leaning with use of the social dimension of Web 2.0 in Phase 4 and

- learning with use of the social dimension of Web 2.0 in Phase 5.

Further research is proposed to comprise the search for factors that enhance the development of students' experience in use of the social dimension of Web 2.0 within five phases of the process of teaching and learning with use of the social dimension of Web 2.0. Use of Web 3.0 and Enterprise 3.0 within the process of teaching and learning with use of the social dimension of Web 2.0 for the development of students' experience in use of Information and Communication Technology is of a common research interest, too.

Further research can also be aimed at searching for relevant methods for evaluation of criteria of the development of students' experience in use of the social dimension of Web 2.0 as well as data obtaining, processing, analyzing and interpretation in the qualitative evaluation research. The qualitative evaluation research can be applied to empirical studies on the process of teaching and learning for the development of students' experience in use of the social dimension of Web 2.0 at bachelor and master level of other tertiary institutions and a comparative research of different countries.

Finally, the qualitative evaluation research for examining efficiency of the process of teaching and learning with use of the social dimension of Web 2.0 for the development of students' competences, namely, mathematical competence and basic competences in science and technology, digital competence, learning to learn competence, social and civic competences, sense of initiative and entrepreneurship, and cultural awareness and expression can be used.

\section{References}

[1] Vossen, G., "Web 2.0: a Buzzword, a serious Development, just Fun, or What?" In: International Joint Conference on e-Business and Telecommunications. Milan, Italy, 2009, pp. IS33-IS40.

[2] Parsons, T., Theorie sozialer Systeme. Opladen: Westdeutscher Verlag, 1976, pp. 9-30.

[3] Luhmann, N., Erkenntnis als Konstruktion. Bern: Benteli, 1988, pp. 1-14.

[4] Mead, G. H., Geist, Identitat, und Gesselschaft. Frankfurt am Main: Suhrkamp, 1973. 
[5] Groeben, N., Handeln, Tun, Verhalten als Einheiten einer verstehend-erklärenden Psychologie. Tübingen: Francke, 1986.

[6] Reich, K., Systemisch-konstruktivistische Pädagogik. Weinheim: Beltz, 2005, pp. 299.

[7] Maslo, E., „Transformative Learning Space for LifeLong Foreign Languages Learning". In: International Nordic-Baltic Region Conference of FIPLV Innovations in Language Teaching and Learning in the Multicultural Context. Riga, Latvia, 2007, pp. 38-46.

[8] Tapscott, D., Williams, A., Wikinomics: How Mass Collaboration Changes Everything. New York: Penguin Books, 2006.

[9] Berners-Lee, T., Weaving the Web: The Original Design and Ultimate Destiny of the World Wide Web. New York: Harper Collins, 2000.

[10] Bassus, O., Wolfgramm, K., “The Innovative Entrepreneurship Training Program at Hochschule Wismar University of Technology, Business and Design". In: Ahrens, A. and Lange, C. (Ed.), First Asian Conference on e-Business and Telecommunications, Berlin: Mensch \& Buch, 2009, pp. 73-81.

[11] Vygotsky, L., "The Development of Scientific Concepts in Childhood". In: L. Vygotsky, Thought and Language. Cambridge: MIT Press; 1934/1962, pp. 82-93.

[12] Zaščerinska, J., Ahrens, A., „Social Dimension of Web 2.0 in Teacher Education: Focus on Peer-Learning". Proceedings of London International Conference on Education (LICE-2010) September 6-8, 2010, London, UK, Published by Infonomics Society, pp. 182-187.

[13] Muresan, L., "The question of quality: are we doing the right things? Are we doing the things right?" In: Grima, A. C., Candelier, M., Fitzpatrick, A., Halink, R., Heyworth, F. (editor), Muresan, L., Newby, D. 2003. Challenges and Opportunities in Language Education. The Contributions of the European Centre for Modern Languages 2000 - 2003. European Centre for Modern Languages Council of Europe Publishing F-67075 Strasbourg cedex, September 2003. Printed in Kapfenberg. pp. 81-90.

[14] Commission of the European Communities, "Efficiency and Equity in European Education and Training Systems". Communication from the Commission to the Council and to the European Parliament. Brussels 08/09/2006,

http://ec.europa.eu/education/policies/2010/doc/comm481_ en.pdf (3 July 2010).

[15] Robbins, D., "Vygotsky's and Leontiev's Nonclassical Psychology Related to Second Language Acquisition". In: D. Cunningham, D. Markus, J. Valdmanis (Eds). International Nordic-Baltic Region Conference of FIPLV Innovations in Language Teaching and Learning in the Multicultural Context 15-16 June, 2007, Riga, Latvia, Rīga: SIA "Izglìtíbas soḷi", 2007, pp. 47-57.
[16] Dirba, M., "Intercultural Learning and Language Education”. In: Aida Kruze, Iris Mortag, Dieter Schulz (Hg.). Sprachen- und Schulpolitik in Multikuturellen Gessellschaften. Leipziger Universitätsverlag, 2007, pp. 101-109.

[17] Mayring, P., On Generalization in Qualitatively Oriented Research. Forum Qualitative Sozialforschung / Forum: Qualitative Social Research, 8(3), Art. 26, 2007, http://nbn-resolving.de/urn:nbn:de:0114-fqs0703262.

[18] Kardoff, E., „Qualitative Evaluation Research”. In: U. Flick, E. Von Kardoff and I. Steinke (Eds). A Companion to Qualitative Research. SAGE, UK, Glasgow, 2004, pp. 137.-142.

[19] Zaščerinska, J., "Social Dimension of Web 2.0 in Teacher Professional Development: Focus on Students' View". In: Bassus, O.; Ahrens, A.; Lange, C. (Ed.), Information and Communication Technologies in Engineering and Business, Berlin: Mensch \& Buch, 2011, pp. 59-77.

[20] Mayring, P., „Qualitative Content Analysis”. In: U. Flick, E. Von Kardoff and I. Steinke (Eds). A Companion to Qualitative Research. SAGE, UK, Glasgow, 2004, p. 266-269. 